\title{
Anti-Inflammatory and Pro-apoptotic Effects of Curcumin and Resveratrol on the Human Lung Fibroblast Cell Line MRC-5
}

\author{
Burkhard Kloesch $^{1^{*}}$, Elisabeth Dietersdorfer ${ }^{1}$, Silvia Loebsch $^{1}$ and Guenter Steiner ${ }^{1,2}$ \\ ${ }^{1}$ Ludwig Boltzmann Institute for Rheumatology and Balneology, Cluster Rheumatology, Balneology and Rehabilitation, Vienna, Austria \\ ${ }^{2}$ Division of Rheumatology, Department of Internal Medicine III, Medical University Vienna, Austria
}

*Corresponding author: Burkhard Kloesch, Ludwig Boltzmann Institute for Rheumatology and Balneology Kurbadstrasse 141100 Vienna, Austria, Tel: +43-1-68009-9800; Fax: +43-1-68009-9805; E-mail: burkhard.kloesch@gmx.at

Rec date: Sep 16, 2014; Acc date: Oct 7, 2014; Pub date: Oct 10, 2014

Copyright: @ 2014 Kloesch B, et al. This is an open-access article distributed under the terms of the Creative Commons Attribution License, which permits unrestricted use, distribution, and reproduction in any medium, provided the original author and source are credited.

\begin{abstract}
Background: The naturally occuring polyphenols curcumin and resveratrol are considered to be powerful antioxidants and anti-inflammatory compounds and both inhibit the proliferation of different types of cancer cells. In the present study, we investigated possible anti-inflammatory and pro-apoptotic effects of curcumin and resveratrol on the human lung fibroblast cell line MRC-5.
\end{abstract}

Methods: MRC-5 cells were stimulated for $6 \mathrm{~h}$ with interleukin (IL)-1 $\beta$ or phorbol 12- myristate 13-acetate (PMA) in the absence or presence of different concentrations of curcumin or resveratrol. The release of interleukin (IL)- 6 was quantified by enzyme-linked immunosorbent assay (ELISA). The modulation in phosphorylation of the transcription factor nuclear factor-kappa B (NF-kB) and mitogen-activated protein kinases (MAPKs) such as $\mathrm{p}^{38}$ and ERK1/2 were analyzed by Western blot. Cytotoxic and pro-apoptotic effects of curcumin and resveratrol were monitored by the measurement of lactate dehydrogenase (LDH) activity and by Annexin-V/7-AAD staining.

Results: Both curcumin and resveratrol effectively attenuated IL-1 $\beta$ and PMA-induced IL-6 expression in MRC-5 cells. Furthermore, curcumin treatment induced apoptosis via caspase-3 signaling and caused endoplasmic reticulum (ER) stress. Salubrinal, an inhibitor of serine/threonine phosphatase PP1, and antioxidants such as Nacetyl-cysteine (NAC), reduced glutathione (GSH) and sodium hydrogen sulfide (NaHS) diminished the cytotoxic effects of curcumin on MRC-5 cells. In contrast to curcumin, resveratrol had no negative effects on cell viability.

Keywords: MRC-5 cells; Curcumin; Resveratrol; IL-6; Apoptosis.

\section{Introduction}

Curcumin (diferuloylmethane) is a yellow pigment found in the rhizome of turmeric (Curcuma longa L., Zingiberaceae) with a wide range of pharmacological activities [1,2]. Antioxidant, anticarcinogenic, anti-inflammatory and pro-apoptotic effects of this compound have been assessed in various in vitro and in vivo systems [3]. Numerous studies have demonstrated its role in suppressing expression of the cell cycle protein cyclin D1 and transcription factors that are implicated in carcinogens is such as nuclear factor kappa-B $(\mathrm{NF}-\mathrm{kB})$ and activator protein-1 (AP-1). Furthermore, curcumin induced programmed cell death (apoptosis) in tumor cells by activating caspases and down-regulating Bcl-2 family proteins [4,5]. Recent reports have also demonstrated that curcumin inhibits proteosomal activity [6], triggers accumulation of cytosolic $\mathrm{Ca}^{2+}[7]$, and disrupts protein disulfide bond formation [8], all of which initiate ER stress response.

Resveratrol (trans-3,4,9,5-trihydroxystilbene) is a natural phytoalexin found in large quantities in grapes and other food products $[9,10]$. Resveratrol was found to have a potent anticarcinogenic activity in several animal models of cancer [9]. The anticarcinogenic properties of resveratrol are closely associated with its antioxidant activity and the ability to inhibit cyclooxygenase-2 (COX-2), hydroperoxidase, protein kinase C (PKC), Bcl-2 phosphorylation, Akt, NF- $\kappa$ B, matrix metalloprotease-9 (MMP-9), and programmed cell death [11-14].

In the present study, we investigated possible anti-inflammatory and pro-apoptotic properties of curcumin and resveratrol in the human lung fibroblast cell line MRC-5. Data demonstrate that both curcumin and resveratrol effectively blocked interleukin (IL)- $1 \beta$ and phorbol 12-myristate 13-acetate (PMA)-induced interleukin (IL)-6 expression in MRC-5 cells. Furthermore, curcumin suppressed activation of NF- $\kappa B$ and inhibited degradation of $I \kappa B a$, respectively. Beside its potent anti-inflammatory properties, curcumin, at high concentrations, had pronounced cytotoxic effects on MRC-5 cells, induced apoptosis and triggered ER stress response via activation of caspase- 3 and phosphorylation of translation initiation factor 2 (eIF-2 $\alpha$ ). In strong contrast to curcumin, resveratrol did not negatively influence cell viability.

\section{Materials and Methods}

\section{Reagents}

Unless stated otherwise, all reagents were from Sigma Aldrich (Vienna, Austria) and C Roth (Karlsruhe, Germany). IL-1 $\beta$ was purchased from ProSpecTany Technogene (Tel Aviv, Israel). Antibodies for p38 MAPK and ERK1/2, NF- $\kappa B$, I $\kappa$ Ba, caspase-3/-7/-9, and eIF-2 $\alpha$ were from Cell Signaling (New England Biolabs, Frankfurt am Main, Germany). 
Citation: Kloesch B, Dietersdorfer E, Loebsch S, Steiner G (2014) Anti-Inflammatory and Pro-apoptotic Effects of Curcumin and Resveratrol on the Human Lung Fibroblast Cell Line MRC-5. Altern Integr Med 3: 174. doi:10.4172/2327-5162.1000174

Page 2 of 6

\section{Cell culture and experimental methods}

The human lung fibroblast cell line MRC-5 was kindly provided by B Lohberger (Department of Orthopaedics, Medical University of Graz, Austria). Cells were cultivated in Dulbecco's modified Eagle's medium (DMEM) supplemented with $10 \%$ heat-inactivated foetal bovine serum (FBS), $50 \mathrm{IU} / \mathrm{ml}$ penicillin, $50 \mu \mathrm{g} / \mathrm{ml}$ streptomycin, and 2 $\mathrm{mmol} / \mathrm{l}-\mathrm{L}$-glutamine in a humidified incubator with $5 \% \mathrm{CO}_{2}$ and $95 \%$ air. Stock solutions of curcumin and resveratrol were prepared with ethanol $(96 \% \mathrm{v} / \mathrm{v})$ and diluted properly into medium. To induce IL-6 expression, MRC- 5 cells were stimulated for 6 h either with IL- $1 \beta$ (10 $\mathrm{ng} / \mathrm{ml})$ or PMA $(100 \mathrm{ng} / \mathrm{ml})$. All experiments were performed in duplicates and were repeated twice.

\section{Lactatdehydrogenase (LDH) assay}

MRC-5 cells were seeded in 12-well cell culture plates ( 2 x 105/well) and cultured overnight in DMEM plus $10 \%$ (v/v) FBS. The next day, culture medium was changed and replaced by DMEM containing $1 \%$ FBS $(\mathrm{v} / \mathrm{v})$ lacking phenol red. Curcumin and resveratrol were added and cells were incubated for another $6 \mathrm{~h}$. LDH activity in cell culture supernatants was determined with a commercially available kit (Roche, Vienna, Austria).

\section{Annexin-V/7-AAD-assay}

MRC-5 cells were cultured overnight in 6-well cell culture plates (6 $\mathrm{x} 105 /$ well) in DMEM supplemented with $10 \%(\mathrm{v} / \mathrm{v})$ FBS. The next day, culture medium was changed and curcumin or resveratrol were added to the desired concentrations and cells were incubated for another $6 \mathrm{~h}$. Then, cells were trypsinized and labeled with the Muse $\mathrm{e}^{\mathrm{TM}}$ Annexin-V \& Dead Cell reagent (Merck-Millipore, Germany). Detection of living cells, cells in the early or late apoptotic stage and dead cells was performed with the Muse ${ }^{\mathrm{TM}}$ Cell Analyzer (MerckMillipore, Germany).

\section{Cytokine measurement}

Ready-to-go enzyme-linked immunosorbent assay (ELISA) kit from ebioscience (Vienna, Austria) was used to quantify IL-6 levels in cell culture supernatants.

\section{Gel electrophoresis and Western blot analysis}

SDS-PAGE and Western blots were performed by standard methods. Briefly, at the end of the experiment, cells were washed twice with PBS $\left(\mathrm{p}^{\mathrm{H}} 7.4\right)$ and lysed with SDS-loading buffer. Cell lysates were boiled for $5 \mathrm{~min}$ at $95^{\circ} \mathrm{C}$ and treated with a short pulse of ultrasound $(10 \mathrm{sec})$ to minimize viscosity. Equal amounts were then loaded onto SDS gels. Proteins were separated on $12 \%$ polyacrylamide mini gels, blotted by semi-dry electrotransfer to nitrocellulose membranes and probed with specific antibodies. Proteins were visualized using RotiLumin (Roth, Karlsruhe, Germany) and the GeneGnome chemiluminescence detection device (Syngene, Cambridge, UK).

\section{Statistical analysis}

Statistical analysis was performed using GraphPad Prism version 5.04. Data were expressed as means \pm SEM. Differences between three or more groups were calculated by 1 and 2-way ANOVA, respectively. A probability level of 0.05 was used to define significance.

\section{Results}

\section{Curcumin and resveratrol attenuate IL-1 $\beta$ and PMA-induced IL-6 expression}

To evaluate possible anti-inflammatory properties of curcumin and resveratrol, MRC- 5 cells were stimulated for $6 \mathrm{~h}$ with IL- $1 \beta$ or PMA in the absence or presence of increasing concentrations of curcumin or resveratrol $(12.5-100 \mu \mathrm{M})$. As shown in Figure 1A, IL-1 $\beta$ induced IL-6 expression in MRC-5 cells to a high extent $(\sim 8 \mathrm{ng} / \mathrm{ml})$. IL-6 production induced by PMA was much less pronounced, approximately 20 -fold lower (Figure $1 \mathrm{~B}$ ). Data show that relatively low concentrations of curcumin $(12.5 \mu \mathrm{M})$ almost completely blocked IL-6 expression, regardless of whether IL-1 $\beta$ or PMA was used for stimulation (Figure 1A and 1B). The inhibitory effect of curcumin on IL-6 expression was much higher compared to that of the same concentration of resveratrol (95 versus $15 \%$ inhibition at $12.5 \mu \mathrm{M}$; Figure 1A). In fact, $100 \mu \mathrm{M}$ resveratrol was required to obtain the same degree of suppression of IL-6 production as observed with $12.5 \mu \mathrm{M}$ curcumin. The half maximal inhibitory concentration $\left(\mathrm{IC}_{50}\right)$ of curcumin on IL-6 expression was estimated by a dose-response curve; $\mathrm{IC}_{50} \sim 5 \mu \mathrm{M}$ (Figure 1C). Next, we investigated whether curcumin may amplify the inhibitory effects of resveratrol on IL-6 expression. MRC-5 cells were stimulated for $6 \mathrm{~h}$ with IL- $1 \beta$ in the absence or presence of resveratrol or resveratrol plus curcumin. As shown in Figure 1D, 50 $\mu \mathrm{M}$ resveratrol reduced IL-6 expression at about $60 \%$, whereas resveratrol in combination with $5 \mu \mathrm{M}$ curcumin blocked IL-6 release almost completely ( $95 \%)$ indicating that resveratrol and curcumin have additive effects.
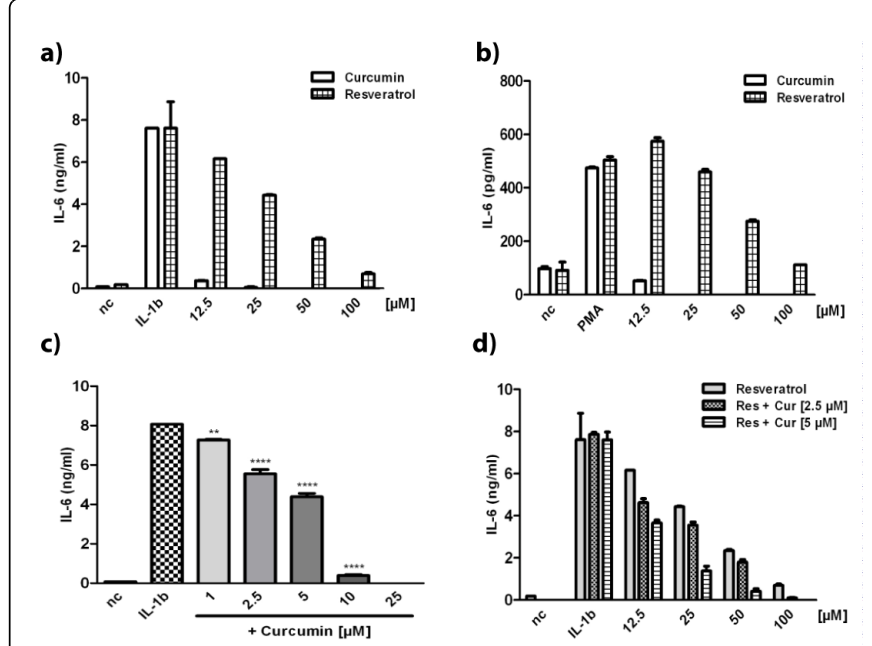

Figure 1: Curcumin and resveratrol diminish IL-1 $\beta$ and PMAinduced IL- 6 expression in MRC-5 cells. Cells were stimulated for 6 $h$ with IL- $1 \beta$ or PMA in the absence or presence of indicated concentrations of curcumin or resveratrol (A, B). (C) Doseresponse curve of curcumin. MRC- 5 cells were stimulated for $6 \mathrm{~h}$ with IL- $1 \beta$ in the absence or presence of indicated concentrations of curcumin. (D) MRC- 5 cells were stimulated for $6 \mathrm{~h}$ with IL- $1 \beta$ in the absence or presence of resveratrol or resveratrol plus curcumin. IL-6 levels in cell culture supernatants were quantified by ELISA. Data from 2 independent experiments are presented as mean \pm $\operatorname{SEM}\left({ }^{* *} \mathrm{p}<0.01 ;{ }^{* * * *} \mathrm{p}<0.0001\right)$. 


\section{Curcumin blocks activation of NF-kB}

Next, we tried to identify potential signaling pathways (NF- $\mathrm{kB}$, etc.) affected by curcumin and resveratrol. MRC- 5 cells were pre-incubated for 30 min with curcumin or resveratrol $(12.5-100 \mu \mathrm{M})$ before being stimulated for $20 \mathrm{~min}$ with IL-1 $\beta$. Activation of NF- $\kappa \mathrm{B}$ (phosphorylation of the $\mathrm{p}^{65}$ subunit at serine 536) and degradation of I $\mathrm{B} \alpha$, respectively, were analyzed by Western blot. As shown in Figure $2 \mathrm{~A}, \mathrm{NF}-\mathrm{kB}$ was rapidly phosphorylated after the addition of IL- $1 \beta$. Interestingly, phosphorylation of NF- $\kappa \mathrm{B}$ and degradation of I $\kappa \mathrm{B} \alpha$ were blocked only at $100 \mu \mathrm{M}$ curcumin, lower concentrations (12.5-50 $\mu \mathrm{M})$, however, were inefficient (Figure 2A). In comparison to curcumin, resveratrol completely failed to inhibit NF- $\mathrm{B}$ activation (Figure $2 \mathrm{~B}$ ). a)

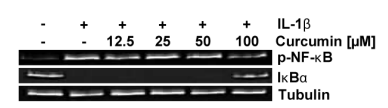

b)

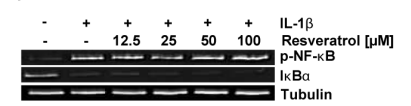

Figure 2: Curcumin inhibits phosphorylation of NF- $\kappa B p^{65}$ in IL- $1 \beta$ stimulated MRC-5 cells. Cells were pre-incubated for $30 \mathrm{~min}$ with indicated concentrations of curcumin or resveratrol before being stimulated for $20 \mathrm{~min}$ with IL-1 $\beta$. Total cell proteins were subjected to SDS-PAGE electrophoresis and blotted onto nitrocellulose membranes. Phospho-NF- $\kappa B$ (p-NF- $\kappa \mathrm{B})$ and I $\mathrm{BB} \alpha$ were detected with specific antibodies; (A) Cells were stimulated with IL-1 $\beta-/+$ curcumin; (B) Cells were stimulated with IL-1 $\beta-/+$ resveratrol.

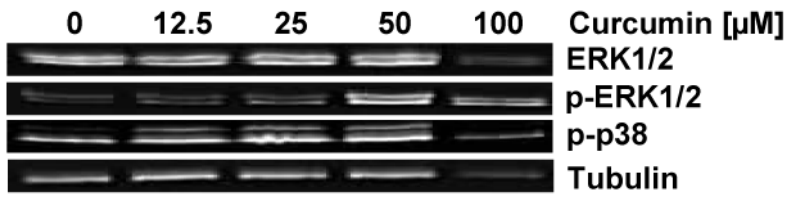

Figure 3: Curcumin induces phosphorylation of ERK1/2. MRC-5 cells were treated for $60 \mathrm{~min}$ with indicated concentrations of curcumin or resveratrol. Total cell proteins were subjected to SDSPAGE electrophoresis and blotted onto nitrocellulose membranes. Phospho-ERK1/2 (p-ERK1/2) and phospho- ${ }^{38}$ MAPK (p-p $\left.{ }^{38}\right)$ were detected with specific antibodies against Thr202/Tyr204 (pERK1/2) and Thr180/Tyr182 (p-p $\left.{ }^{38}\right)$; (A), Curcumin-treated cells; (B), Resveratrol-treated cells.

\section{Curcumin activates extracellular signal-regulated kinase (ERK)-1/2}

Besides NF- $\kappa$ B, mitogen-activated protein kinases (MAPKs) play a central role in proliferation, gene expression, differentiation, cell survival, and apoptosis. Therefore, we investigated the effects of curcumin and resveratrol on MAPK activation ( $\mathrm{p}^{38}$ MAPK and ERK1/2) in MRC-5 cells. Cells were treated for 60 min with different concentrations of curcumin or resveratrol $(12.5-100 \mu \mathrm{M})$ and phosphorylation of $\mathrm{p}^{38}$ MAPK and ERK1/2 was analyzed by Western blot. As shown in Figure 3, phosphorylation of ERK1/2 was induced at $50 \mu \mathrm{M}$ curcumin, whereas lower concentrations did not affect ERK1/2. Notably, treatment of MRC-5 cells with $100 \mu \mathrm{M}$ curcumin led to a dramatic decrease of total protein content (Figure 3) indicating that curcumin at high concentrations had cytotoxic effects. In contrast to ERK1/2, $\mathrm{p}^{38}$ MAPK was only slightly affected (Figure 3).

\section{Curcumin induces cell death through apoptosis}

To analyze cytotoxic and pro-apoptotic effects of curcumin and resveratrol, we measured lactate dehydrogenase (LDH) activity in cell culture supernatants and performed Annexin-V/7-AAD staining of curcumin and resveratrol-treated cells. Treatment of MRC- 5 cells with $25 \mu \mathrm{M}$ curcumin led to a significant increase in LDH activity (Figure 4A) whereas resveratrol, however, did not. Next, we asked whether cell death observed in curcumin-treated cells was due to apoptosis. MRC-5 cells were incubated for $6 \mathrm{~h}$ with increasing concentrations of curcumin $(12.5-100 \mu \mathrm{M})$ and apoptotic activity was analyzed by Annexin-V/7-AAD staining. Data show that treatment with $12.5 \mu \mathrm{M}$ curcumin had no significant effect on cell viability (Figure 4B). At 25 $\mu \mathrm{M}$ curcumin, about $40 \%$ of the total cell population was in the early apoptotic stage, at $50 \mu \mathrm{M}$, already $80 \%$. At $100 \mu \mathrm{M}$ curcumin, $90 \%$ of the cells were in the late apoptotic/dead stage (Figure 4B). In contrast, treatment of MRC-5 cells with resveratrol (up to $24 \mathrm{~h}$ ) did not negatively affect cell viability (data not shown). In addition, we investigated whether apoptosis was induced via the caspase signaling pathway. As shown in Figure 4C, degradation of pro-caspase-3 was evident $1 \mathrm{~h}$ post-treatment. Interestingly, a decrease of procaspase-7/-9 could not be detected (Figure 4C). Confirming the data shown in Figure 3, a dramatic decline in total protein content was observed at $100 \mu \mathrm{M}$ curcumin (Figure $4 \mathrm{C}$ ) suggesting that curcumin at high concentrations led to irreversible cell damage. In cells treated with resveratrol, however, caspases were not activated (Figure 4E).

\section{Curcumin induces endoplasmic reticulum (ER) stress}

Phosphorylation of the alpha subunit of the eukaryotic initiation factor-2 (eIF-2 $\alpha$ ) is a well-documented mechanism of down-regulating protein synthesis triggered by agents that induce apoptosis, ER stress and protein misfolding. To clarify whether curcumin may also induce ER stress in MRC-5 cells, cells were left untreated or were exposed for $30 \mathrm{~min}$ to curcumin $(6.25-100 \mu \mathrm{M})$. As shown in Figure 5A, treatment of cells with $100 \mu \mathrm{M}$ curcumin resulted in marked phosphorylation of eIF-2a. Salubrinal (Sal) as an inhibitor of serine/threonine phosphatase PP1 blocks eIF-2 $\alpha$ dephosphorylation. When MRC-5 cells were treated for $6 \mathrm{~h}$ with $25 \mu \mathrm{M}$ curcumin in the presence of Sal $(50 \mu \mathrm{M})$, the survival rate significantly increased (> 40\%) (Figure 5B and 5C). At higher concentrations of curcumin, however, Sal failed to maintain cell viability (Figure 5A). Interestingly, the caspase inhibitor Q-VD-OPh did not reduce curcumin-induced cell death (Figure 5B).

\section{Antioxidants and the MEK1/2 inhibitor U0126 prevent curcumin-induced cell death}

Antioxidants such as N-acetylcysteine (NAC), reduced glutathione (GSH) and sodium hydrogen sulfide (NaHS) are substances with known cytoprotective properties and potent scavengers of reactive oxygen species (ROS). To study whether curcumin-induced cytotoxicity might be diminished by these substances, MRC- 5 cells were loaded for $1 \mathrm{~h}$ with NAC, GSH (each $1 \mathrm{mM})$ or NaHS $(0.1 \mathrm{mM})$ before being treated for $6 \mathrm{~h}$ with curcumin $(25 \mu \mathrm{M})$. In comparison to curcumin-treated cells, NAC reduced LDH activity by about $80 \%$, GSH and NaHS by about $50-60 \%$, suggesting that antioxidants had strong beneficial effects on cell viability (Figure 6). The MEK1/2 
inhibitor U0126, which blocks activation of ERK1/2, also reduced curcumin-induced cell death ( 50\%) (Figure 6).
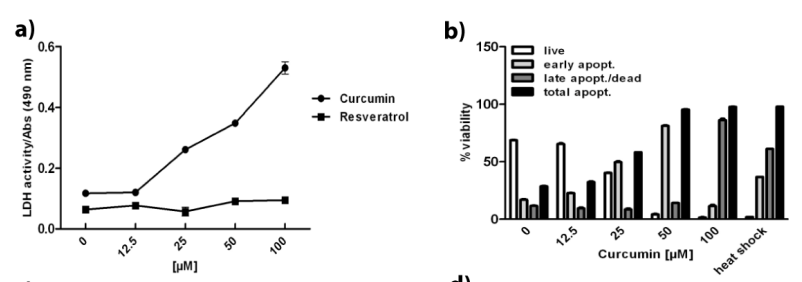

c)

d)
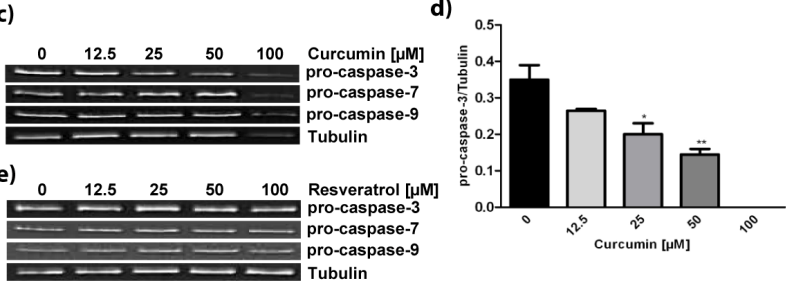

Figure 4: Cytotoxic and pro-apoptotic effects of curcumin and resveratrol on MRC-5 cells.(A) Cells were treated for $6 \mathrm{~h}$ with indicated concentrations of curcumin or resveratrol and $\mathrm{LDH}$ activity was then measured in cell culture supernatants. (B) MRC-5 cells were treated for $6 \mathrm{~h}$ with indicated concentrations of curcumin and cells were stained with Annexin-V/7-AAD to differentiate between cells being alive or in the early or late apoptotic stage. (C, E) MRC-5 cells were treated for $1 \mathrm{~h}$ with indicated concentrations of curcumin or resveratrol and activation of caspase-3/-7/-9 was analyzed by Western blot. (D) Levels of pro-caspase- 3 in curcumintreated cells were semi-quantitatively determined by densitometry. Data are representative of 2 experiments $\left({ }^{*} \mathrm{p}<0.05 ;{ }^{* *} \mathrm{p}<0.01\right)$.

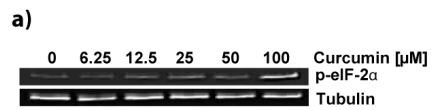

b)
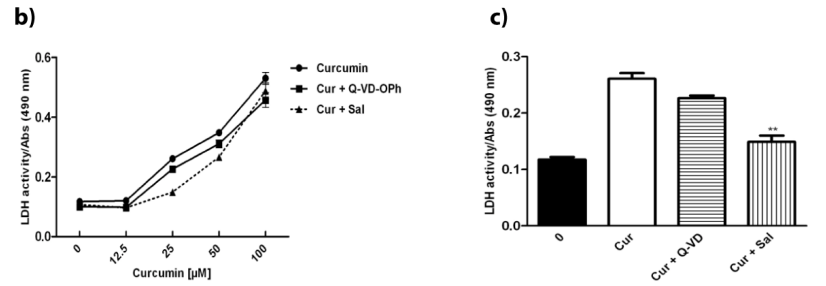

Figure 5: Curcumin induces ER stress in MRC-5 cells. Cells were treated for $30 \mathrm{~min}$ with indicated concentrations of curcumin. Total cell proteins were subjected to SDS-PAGE and blotted onto nitrocellulose membranes. (A) Phospho-eIF-2 $\alpha$ (p-eIF-2 $\alpha$ ) was detected with a specific antibody against ser51. (B, C) Cells were treated for $6 \mathrm{~h}$ with indicated concentrations of curcumin in the absence or presence of Salubrinal $(50 \mu \mathrm{M})$ or Q-VD-OPh $(25 \mu \mathrm{M})$ and LDH activity was then monitored in cell culture supernatants.

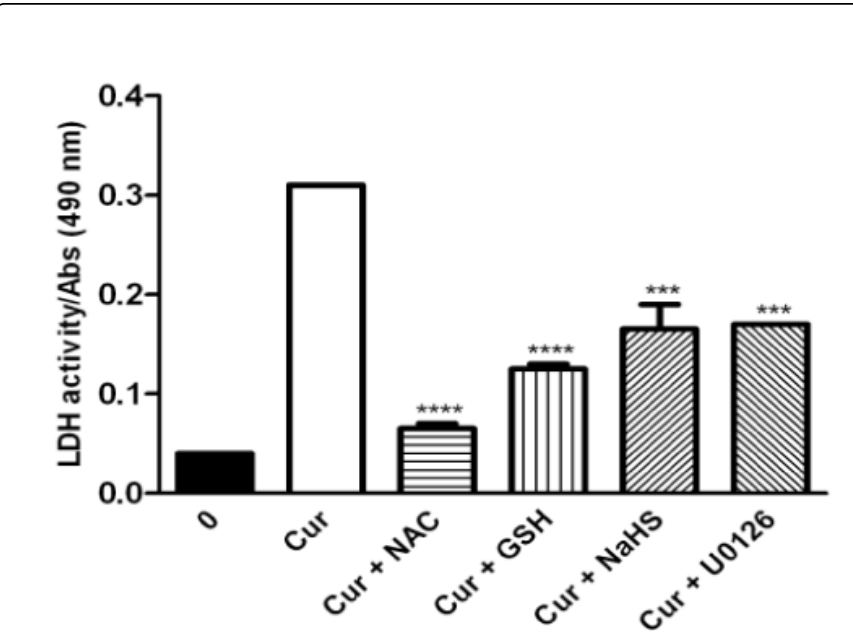

Figure 6: NAC, GSH, NaHS and U0126 reduce the cytotoxic effects of curcumin in MRC- 5 cells. Cells were loaded for $1 \mathrm{~h}$ with NAC, GSH (each $1 \mathrm{mM})$, NaHS $(0.1 \mathrm{mM})$ or U0126 $(10 \mu \mathrm{M})$ and were then incubated with $25 \mu \mathrm{M}$ curcumin for another $6 \mathrm{~h}$. LDH activity was measured in cell culture supernatants. Data from 2 independent experiments are presented as mean \pm SEM $\left({ }^{* * *} \mathrm{p}<0.001 ;{ }^{* * * *} \mathrm{p}<0.0001\right)$.

\section{Discussion}

Our data demonstrate that the phytochemicals curcumin and resveratrol had pronounced anti-inflammatory activities in the human lung fibroblast cell line MRC-5. Both compounds diminished IL- $1 \beta$ and PMA-induced IL- 6 gene expression in a concentration-dependent manner. In the NF- $\kappa B$ signaling cascade, NF- $\kappa B$ once activated immediately initiates the transcription of IL- 6 mRNA and many other pro-inflammatory genes (TNF- $\alpha$, IL8, COX-2, etc.). Our data show that curcumin at $12.5 \mu \mathrm{M}$ almost completely blocked IL-6 expression in MRC-5 cells. In strong contrast, Western blot analysis revealed that curcumin suppressed phosphorylation of NF- $\mathrm{BB}$ only at a concentration of $100 \mu \mathrm{M}$. It has been shown that besides the phosphorylation of the NF- $\kappa B$ subunit $\mathrm{p}^{65}$ (RelA) at serine 276/536, acetylation at lysine 218,221 , and 310 differentially regulates the DNA binding activity of RelA along with its assembly with I $\mathrm{B} a$, and transcriptional activity [15]. The acetyltransferases p300 and CBP appear to play a major role in the in vivo acetylation of RelA [16]. Balasubramanyam et al. has been reported that curcumin repressed acetylation of histone/nonhistone proteins and histone acetyltransferase-dependent chromatin transcription [17]. Therefore, we suggest that the inhibitory effects of curcumin on IL-6 expression may be due to its ability to prevent acetylation of RelA but in further experiments we will clarify this hypothesis. In contrast to curcumin, the inhibitory effect of resveratrol on IL-6 expression was significantly lower ( $\sim 10$ fold less). Western blot data demonstrate that resveratrol blocked neither RelA phosphorylation nor degradation of IкBa. Recently, it has been reported that activation of Sirtuin1 (Sirt1) by resveratrol inhibited TNF- $\alpha$-induced inflammation in mouse embryonic fibroblasts [18]. Sirt1, a mammalian homolog of Sir2, is a $\mathrm{NAD}^{+}$-dependent class III histone deacetylase. Sirtl is involved in a variety of physiological and pathophysiological processes, such as cell growth, inflammation and modulation of cancer cell metabolism 
$[19,20]$. Knockout of Sirtl led to an increase in cytokine expression, whereas Sirt1 activation inhibited production of TNF- $\alpha$, monocyte chemoattractant protein 1 (MCP-1) and IL-8 [21]. Suppression of proinflammatory cytokines production by Sirtl is highly related to its negative regulation of NF- $\kappa \mathrm{B}$ activity via the deacetylation of the RelA subunit at lysine 310 [22]. Based on these findings we conclude that curcumin and resveratrol are both anti-inflammatory compounds but may act by different molecular mechanisms. On the one hand, curcumin may prevent acetylation of RelA at lysine 310 thereby blocking acetyltransferase p300 and CBP, while resveratrol, on the other hand, may induce deacetylation of RelA by activation of Sirt1.

Caspases play a key role in programmed cell death mediated by various apoptotic stimuli [23]. Curcumin was found to act as an antioxidant at low dose, whereas at higher concentrations its prooxidant properties prevailed, a virtue that may be of importance in cell apoptosis [24]. We demonstrated that curcumin, even at relatively low concentrations $(25 \mu \mathrm{M})$ had negative effects on cell viability. This finding stays in contrast to the results of another group which has been demonstrated that NIH3T3 mouse fibroblasts and HEK-293 cells were largely resistant to curcumin treatment and displayed minimal cell death toxicity at $100 \mu \mathrm{M}$ suggesting different sensitivities of distinct cell types to curcumin [25]. Additionally, our data show that curcumin induced cell death through apoptosis via activation of caspase-3. Apoptosis is often associated with the induction of endoplasmic reticulum (ER) stress [26]. Phosphorylation of the alpha unit of the eukaryotic initiation factor-2 (eIF-2a) is a marker for ER stress [27]. Our findings demonstrate that curcumin besides its capability to induce apoptosis also induced phosphorylation of eIF-2a. Inhibition of dephosphorylation eIF- $2 \alpha$ by Salubrinal significantly protected cells from curcumin-induced cell damage. Furthermore, antioxidants such as NAC, GSH and NaHS also increased the survival rate of curcumintreated cells. It has recently been shown that in the leukemic monocyte cell line THP-1, curcumin-induced apoptosis was induced via phosphorylation of ERK1/2 [28]. We showed that in MRC-5 cells, phosphorylation of ERK1/2 was induced at $50 \mu \mathrm{M}$ curcumin, a concentration which definitely led to programmed cell death. Therefore, we suggest that the underlying mechanisms for the initiation of apoptosis in THP-1 and MRC-5 cells might be similar. In contrast to curcumin, resveratrol had no negative influence on cell viability and did not induce apoptosis.

\section{Conclusion}

Recently, we reported about the anti-inflammatory and proapoptotic effects of curcumin on human synovial fibroblasts derived from rheumatoid arthritis patients [29,30]. In the present study, we investigated the effects of curcumin and resveratrol on the human lung fibroblast cell line MRC-5 and data demonstrated that the effects of curcumin were very similar. In accordance with our results, Smith et al. reported that curcumin inhibited fibrosis-related effects in idiopathic pulmonary fibrosis (IPF), a progressive and fatal lung disease for which not therapy has been identified. Curcumin reduced lung fibroblast cell proliferation and inhibited collagen secretion by IPF fibroblasts [31]. The potential use of curcumin and resveratrol as a therapeutic option is very limited through its low bioavailability. Therefore, in cooperation with the Department of Nanobiotechnology (University of Natural Resources and Life Sciences, Vienna, Austria) we plan to evaluate the effects of so called "CurcuEmulsomes" in our in vitro assays. CurcuEmulsomes are spherical solid nanoparticles and increase the bioavailability of curcumin by up to 10.000 fold as recently reported $[31,32]$. CurcuEmulsomes might be a valuable tool to study the beneficial effects of curcumin in various therapeutic applications in vivo.

\section{References}

1. Aggarwal BB, Kumar A, Bharti AC (2003) Anticancer potential of curcumin: preclinical and clinical studies. Anticancer Res 23: 363-398.

2. Ammon HP, Wahl MA (1991) Pharmacology of Curcuma longa. Planta Med 57: 1-7.

3. Park C, Moon DO, Choi IW, Choi BT, Nam TJ, et al. (2007) Curcumin induces apoptosis and inhibits prostaglandin $\mathrm{E}(2)$ production in synovial fibroblasts of patients with rheumatoid arthritis. Int J Mol Med 20: 365-372.

4. Bush JA, Cheung KJ Jr, Li G (2001) Curcumin induces apoptosis in human melanoma cells through a Fas receptor/caspase-8 pathway independent of p53. Exp Cell Res 271: 305-314.

5. Shishodia S, Chaturvedi MM, Aggarwal BB (2007) Role of curcumin in cancer therapy. Curr Probl Cancer 31: 243-305.

6. Jana NR, Dikshit P, Goswami A, Nukina N (2004) Inhibition of proteasomal function by curcumin induces apoptosis through mitochondrial pathway. J Biol Chem 279: 11680-11685.

7. Logan-Smith MJ, East JM, Lee AG (2002) Evidence for a global inhibitorinduced conformation change on the $\mathrm{Ca}(2+)$-ATPase of sarcoplasmic reticulum from paired inhibitor studies. Biochemistry 41: 2869-2875.

8. Pae HO, Jeong SO, Jeong GS, Kim KM, Kim HS, et al. (2007) Curcumin induces pro-apoptotic endoplasmic reticulum stress in human leukemia HL-60 cells. Biochem Biophys Res Commun 353: 1040-1045.

9. Jang M, Cai L, Udeani GO, Slowing KV, Thomas CF, et al. (1997) Cancer chemopreventive activity of resveratrol, a natural product derived from grapes. Science (Wash DC) 275: 218-220.

10. Soleas GJ, Diamandis EP, Goldberg DM (1997) Wine as a biological fluid: history, production, and role in disease prevention. J Clin Lab Anal 11: 287-313.

11. Banerjee S, Bueso-Ramos C, Aggarwal BB (2002) Suppression of 7,12dimethylbenz(a)anthracene-induced mammary carcinogenesis in rats by resveratrol: role of nuclear factor-kappaB, cyclooxygenase 2 , and matrix metalloprotease 9. Cancer Res 62: 4945-4954.

12. Baur JA, Sinclair DA (2006) Therapeutic potential of resveratrol: the in vivo evidence. Nat Rev Drug Discov 5: 493-506.

13. Bhat KPL, Kosmeder JW 2nd, Pezzuto JM (2001) Biological effects of resveratrol. Antioxid Redox Signal 3: 1041-1064.

14. Dorrie J, Gerauer H, Wachter Y, Zunino SJ (2001) Resveratrol induces extensive apoptosis by depolarizing mitochondrial membranes and activating caspase-9 in acute lymphoblastic leukemia cells. Cancer Res 61: 4731-4739.

15. Chen LF, Williams SA, Mu Y, Nakano H, Duerr JM, et al. (2005) NFkappaB RelA phosphorylation regulates RelA acetylation. Mol Cell Biol 25: 7966-7975.

16. Chen LF, Mu Y, Greene WC (2002) Acetylation of RelA at discrete sites regulates distinct nuclear functions of NF-kappaB. EMBO J 21: 6539-6548.

17. Balasubramanyam K, Varier RA, Altaf M, Swaminathan V, Siddappa NB, et al. (2004) Curcumin, a novel p300/CREB-binding protein-specific inhibitor of acetyltransferase, represses the acetylation of histone/ nonhistone proteins and histone acetyltransferase-dependent chromatin transcription. J Biol Chem 279: 51163-51171.

18. Zhu X, Liu Q, Wang M, Liang M, Yang X, et al. (2011) Activation of Sirt1 by resveratrol inhibits TNF-Î \pm induced inflammation in fibroblasts. PLoS One 6: e27081.

19. Howitz KT, Bitterman KJ, Cohen HY, Lamming DW, Lavu S, et al. (2003) Small molecule activators of sirtuins extend Saccharomyces cerevisiae lifespan. Nature 425: 191-196. 
Citation: Kloesch B, Dietersdorfer E, Loebsch S, Steiner G (2014) Anti-Inflammatory and Pro-apoptotic Effects of Curcumin and Resveratrol on the Human Lung Fibroblast Cell Line MRC-5. Altern Integr Med 3: 174. doi:10.4172/2327-5162.1000174

Page 6 of 6

20. Kojima K, Ohhashi R, Fujita Y, Hamada N, Akao Y, et al. (2008) A role for SIRT1 in cell growth and chemoresistance in prostate cancer PC3 and DU145 cells. Biochem Biophys Res Commun 373: 423-428.

21. Yang SR, Wright J, Bauter M, Seweryniak K, Kode A, et al. (2007) Sirtuin regulates cigarette smoke-induced proinflammatory mediator release via RelA/p65 NF-kappaB in macrophages in vitro and in rat lungs in vivo: implications for chronic inflammation and aging. Am J Physiol Lung Cell Mol Physiol 292: L567-576.

22. Yeung F, Hoberg JE, Ramsey CS, Keller MD, Jones DR, et al. (2004) Modulation of NF-kappaB-dependent transcription and cell survival by the SIRT1 deacetylase. EMBO J 23: 2369-2380.

23. Philchenkov A, Zavelevich M, Kroczak TJ, Los M (2004) Caspases and cancer: mechanisms of inactivation and new treatment modalities. Exp Oncol 26: 82-97.

24. Schröder M, Kaufman RJ (2005) ER stress and the unfolded protein response. Mutat Res 569: 29-63.

25. Manson MM (2005) Inhibition of survival signalling by dietary polyphenols and indole-3-carbinol. Eur J Cancer 41: 1842-1853.

26. Bakhshi J, Weinstein L, Poksay KS, Nishinaga B, Bredesen DE, et al. (2008) Coupling endoplasmic reticulum stress to the cell death program in mouse melanoma cells: effect of curcumin. Apoptosis 13: 904-914.
27. Harding HP, Calfon M, Urano F, Novoa I, Ron D (2002) Transcriptional and translational control in the Mammalian unfolded protein response. Annu Rev Cell Dev Biol 18: 575-599.

28. Boyce M, Bryant KF, Jousse C, Long K, Harding HP, et al. (2005) A selective inhibitor of eIF2alpha dephosphorylation protects cells from ER stress. Science 307: 935-939.

29. Yang CW, Chang CL, Lee HC, Chi CW, Pan JP, et al. (2012) Curcumin induces the apoptosis of human monocytic leukemia THP-1 cells via the activation of JNK/ERK pathways. BMC Complement Altern Med 12: 22.

30. Kloesch B, Becker T, Dietersdorfer E, Kiener H, Steiner G (2013) Antiinflammatory and apoptotic effects of the polyphenol curcumin on human fibroblast-like synoviocytes. Int Immunopharmacol 15: 400-405.

31. Smith MR, Gangireddy SR, Narala VR, Hogaboam CM, Standiford TJ, et al. (2010) Curcumin inhibits fibrosis-related effects in IPF fibroblasts and in mice following bleomycin-induced lung injury. Am J Physiol Lung Cell Mol Physiol 298: L616-625.

32. Ucisik MH, Küpcü S, Schuster B, Sleytr UB (2013) Characterization of CurcuEmulsomes: nanoformulation for enhanced solubility and delivery of curcumin. J Nanobiotechnology 11: 37. 